\title{
Nonresection management of the pancreas for grade III and IV blunt pancreatic injuries in children: a single center's experience
}

\author{
Dan Zhang ${ }^{1 \dagger}$, Jiayu Yan ${ }^{1 \dagger}$, Sarah Tan Siyin ${ }^{1}$, Wenbo Pang ${ }^{1}$ and Yajun Chen ${ }^{1,2^{*}}$
}

\begin{abstract}
Background: The treatment of high-grade (III/IVN) blunt pancreatic injuries remains controversial. The study aims to summarize and evaluate nonresection management of the pancreas for grade III and IV blunt pancreatic injuries in children.

Methods: Twenty children [6.9 (3-12) years] treated at our center between January 2010 and June 2018 were included in this study. Their medical records and the outpatient follow-up data within 12 weeks after discharge were retrospectively reviewed. Long-term follow-up was conducted by telephone in February 2020.

Results: Nine children developed complications, including 8 pancreatic pseudocysts and 1 abdominal infection, after treatment at external hospitals and were transferred to our center with an average length of stay of 33.8 (863) days. Eleven children were admitted to our hospital directly after injury, with an average length of stay of 47.5 (23-69) days. One child underwent emergency laparotomy for hemorrhagic shock and Roux-en-Y drainage of the distal pancreas. The remaining 10 children received conservative treatment: 7 developed pancreatic pseudocysts, 2 developed abdominal infections, and 1 recovered uneventfully. For children with pancreatic pseudocysts (15/20, 75.0\%), 4 recovered after conservative treatment, 4 recovered after percutaneous puncture, 5 recovered after external drainage of the cyst, and 2 recovered after alimentary tract anastomosis. Three children (3/20,15.0\%) who developed abdominal infection recovered after abdominal irrigation and drainage. No child was admitted to the ICU or died. Four children (4/20, 20.0\%) developed local pancreatic atrophy within 12 weeks after discharge, but no other long-term complications were observed.

Conclusions: Nonresection management of the pancreas could be a feasible option for children with grade III and IV blunt pancreatic injuries. Regular long-term follow-up is essential in terms of pancreatic function, especially in patients with pancreatic atrophy.
\end{abstract}

Keywords: Pancreatic injury, Nonresection management, Pancreatic pseudocysts, Pancreatic atrophy

\section{Background}

The treatment of blunt pancreatic injuries in children, especially high-grade injuries (III/IV/V) involving the main pancreatic duct, remains controversial. On the one

\footnotetext{
*Correspondence: chenyajunmd@126.com

Dan Zhang and Jiayu Yan are first authors

'Department of General Surgery, Beijing Children's Hospital, National Center of Children's Health, Capital Medical University, Beijing, China

${ }^{2}$ Beijing, People's Republic of China
}

hand, there is a low incidence of pancreatic injury, accounting for less than $1.0 \%$ of traumas in children. The unavailability of an accurate medical history, unique retroperitoneal location, obscure clinical presentation particularly in children, and low sensitivity and specificity of frequently used modalities, such as serum amylase, lipase levels, computed tomography (CT) and ultrasound (US), may cause difficulty in the diagnosis at

(c) The Author(s). 2021 Open Access This article is licensed under a Creative Commons Attribution 4.0 International License, which permits use, sharing, adaptation, distribution and reproduction in any medium or format, as long as you give appropriate credit to the original author(s) and the source, provide a link to the Creative Commons licence, and indicate if changes were made. The images or other third party material in this article are included in the article's Creative Commons licence, unless indicated otherwise in a credit line to the material. If material is not included in the article's Creative Commons licence and your intended use is not permitted by statutory regulation or exceeds the permitted use, you will need to obtain permission directly from the copyright holder. To view a copy of this licence, visit http://creativecommons.org/licenses/by/4.0/ The Creative Commons Public Domain Dedication waiver (http://creativecommons.org/publicdomain/zero/1.0/) applies to the data made available in this article, unless otherwise stated in a credit line to the data. 
initial presentation $[1,2]$. On the other hand, there is no ideal standardized nonoperative management or surgical treatment that can effectively reduce mortality and related complications in children with high-grade blunt pancreatic injuries $[3,4]$.

Therefore, this study aimed to clarify the feasibility and efficacy of nonresection management of the pancreas in children with high-grade blunt pancreatic injuries.

\section{Methods}

\section{Design and patients}

This study adheres to the ethical principles of the Declaration of Helsinki. After approval of informed consent for consent waiver from the Ethics Committee of Beijing Children's Hospital (2020-k-12), the medical record system at Children's National Medical Center, China, was retrospectively searched for children diagnosed with "pancreatic injury" between January 2010 and June 2018. Their medical information, including demographics, imaging data and treatments, was analyzed. Children who were diagnosed with high-grade pancreatic injuries $(n=$ 23) based on guidelines from the Organ Injury Scale grading of the American Association for the Surgery of Trauma (AAST-OIS) were included (Table 1) [5].

\section{Principles of diagnosis}

All children with suspected pancreatic injury were first examined in our center by the abdominal US. Repeat US was performed to assess progress. Regardless of positive US findings, contrast-enhanced computed tomography (CE-CT) or magnetic resonance imaging (MRI) including magnetic resonance cholangiopancreatography (MRCP), was performed to assess the grade of blunt pancreatic injury for 24-48 h after the vital signs became stable. Typical CE-CT, MRI and MRCP images of grade III and IV blunt pancreatic injuries are shown in Fig. 1. Endoscopic retrograde cholangiopancreatography (ERCP) is not routinely carried out in our center.

\section{Principles of treatment}

The children with blunt pancreatic injury were admitted to the Department of General Surgery in our center. The treatments were performed in accordance with the center's regulations (Fig. 2). Except for children with gastrointestinal injury or continued hemorrhagic shock after initial blood transfusion, all children received conservative treatments, nil-per-os (NPO), somatostatin injected continuously with a microinfusion pump until no symptoms after oral intake or treatment by external drainage and internal drainage $(3.5-5 \mu \mathrm{g} / \mathrm{kg} / \mathrm{h}$ in children until the same dosage as adults), intravenous omeprazole inhibition of acid secretion until oral intake (1-2 $\mathrm{mg} / \mathrm{kg}$ in children until the same dosage as adults), anti-infection treatment, total parenteral nutrition (TPN) and enteral nutrition (EN). Severe abdominal infection was mainly based on abdominal pain, high fever, signs of peritonitis and elevated laboratory indicators including WBC, CRP and procalcitonin after conservative treatment. It was relieved by simple, not continuous peritoneal lavage and drainage, which was achieved through open or laparoscopic surgical techniques, and included opening the lesser omental sac, peritoneal irrigation, and placing the abdominal drainage tube [6-8]. For children who developed immature pancreatic pseudocysts (PCs) during conservative treatment, external drainage was performed after US-guided percutaneous drainage failed (Fig. 3). The indication for US-guided percutaneous drainage was enlargement measured over $5 \mathrm{~cm}$ in diameter or threatening rupture of the acute pseudocysts and chronic pseudocysts causing abdominal symptoms or recurring fever $[9,10]$. The indication for external drainage was US localization failure, no relief of symptoms, and no change or enlargement in PCs after US-guided percutaneous drainage. The criteria for removing external drainage included the following: 1) drainage fluid < $5 \mathrm{ml}$ per day during oral intake; 2) no symptoms when the drainage tube was clipped for $48-72 \mathrm{~h}$ during oral intake; and 3) no change in PCs monitored by the US when the drainage tube was clipped for $48-72 \mathrm{~h}$ during oral intake. For children with mature PCs after

Table 1 Injury scoring scale from the American Association for the Surgery of Trauma

\begin{tabular}{lll}
\hline Grade & Injury & Description \\
\hline I & Hematoma & Minor contusion without duct injury \\
& Laceration & Superficial laceration without duct injury \\
III & Hematoma & Major contusion without duct injury or tissue loss \\
IV & Laceration & Major laceration without duct injury or tissue loss \\
V & Laceration & Distal transection or parenchymal injury with duct injury \\
\hline
\end{tabular}

a Proximal pancreas is to the patients' right of the superior mesenteric vein 

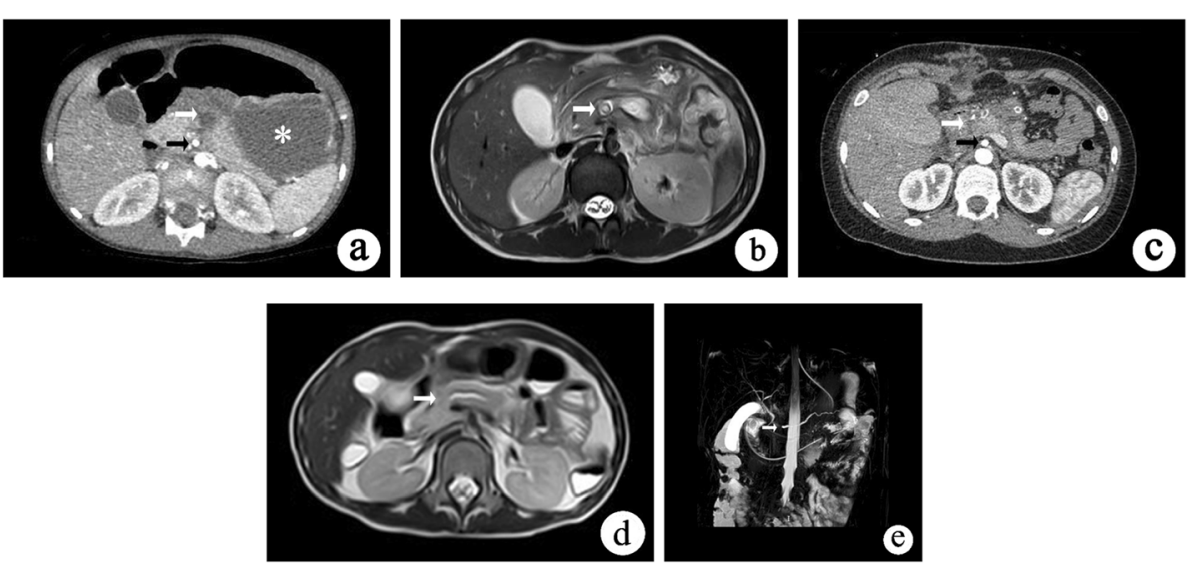

Fig. 1 Typical imaging results indicated by abdominal CE-CT and MRI examinations in children who sustained grade III and IV injuries (white arrow: transection or parenchymal injury with duct injury; black arrow: superior mesenteric artery; asterisk: pancreatic pseudocysts). a-b CE-CT and MRI, axial scan: grade III pancreatic injury, with lesion in the distal part of the duct on the left side of superior mesenteric artery or the spine. c-d CE-CT and MRI, axial scan: grade IV pancreatic injury, with lesion in the proximal part of the duct on the right side of superior mesenteric artery or the spine. e MRCP: grade IV pancreatic injury, with lesion in the proximal part of the duct on the right side of the spine

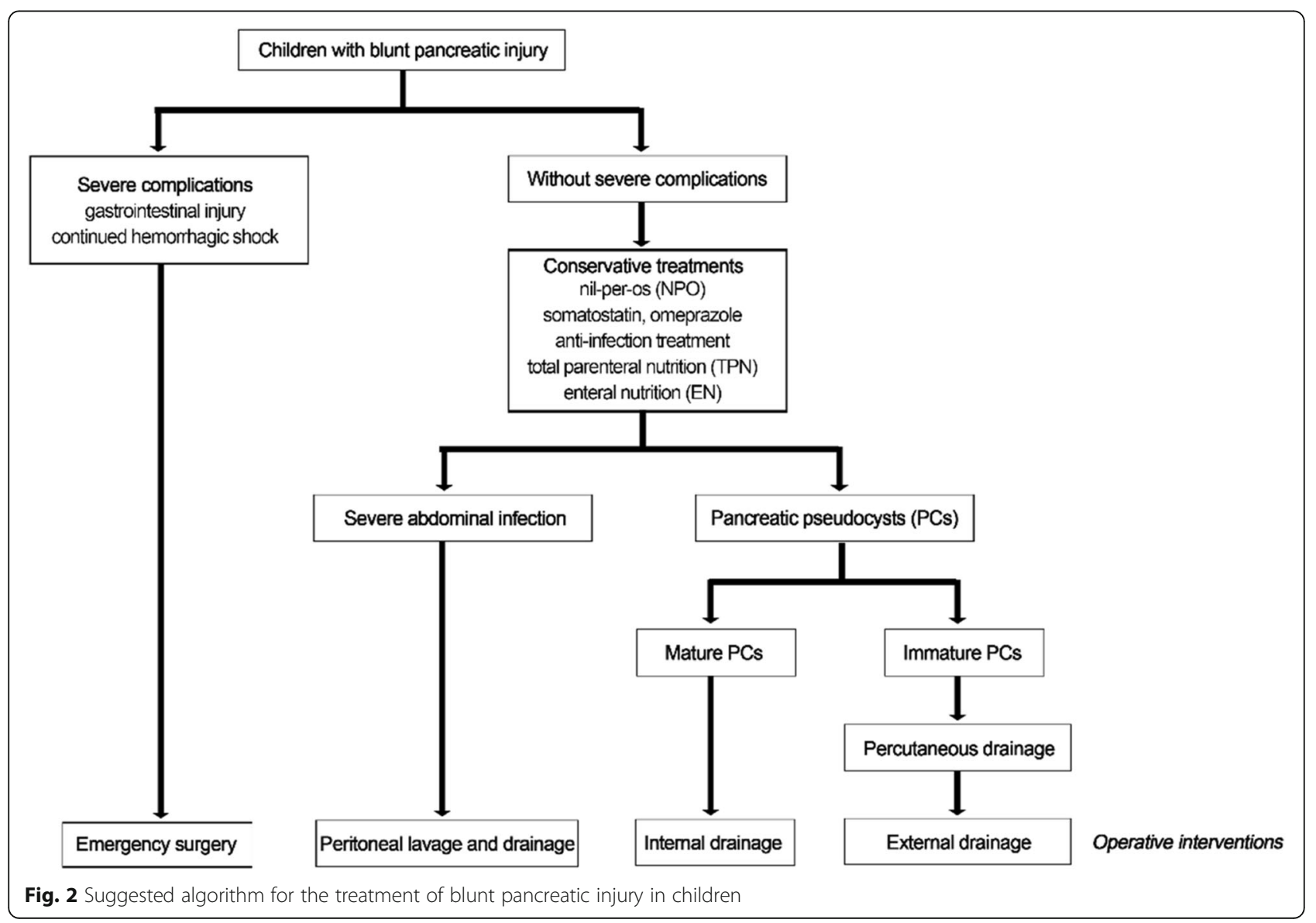



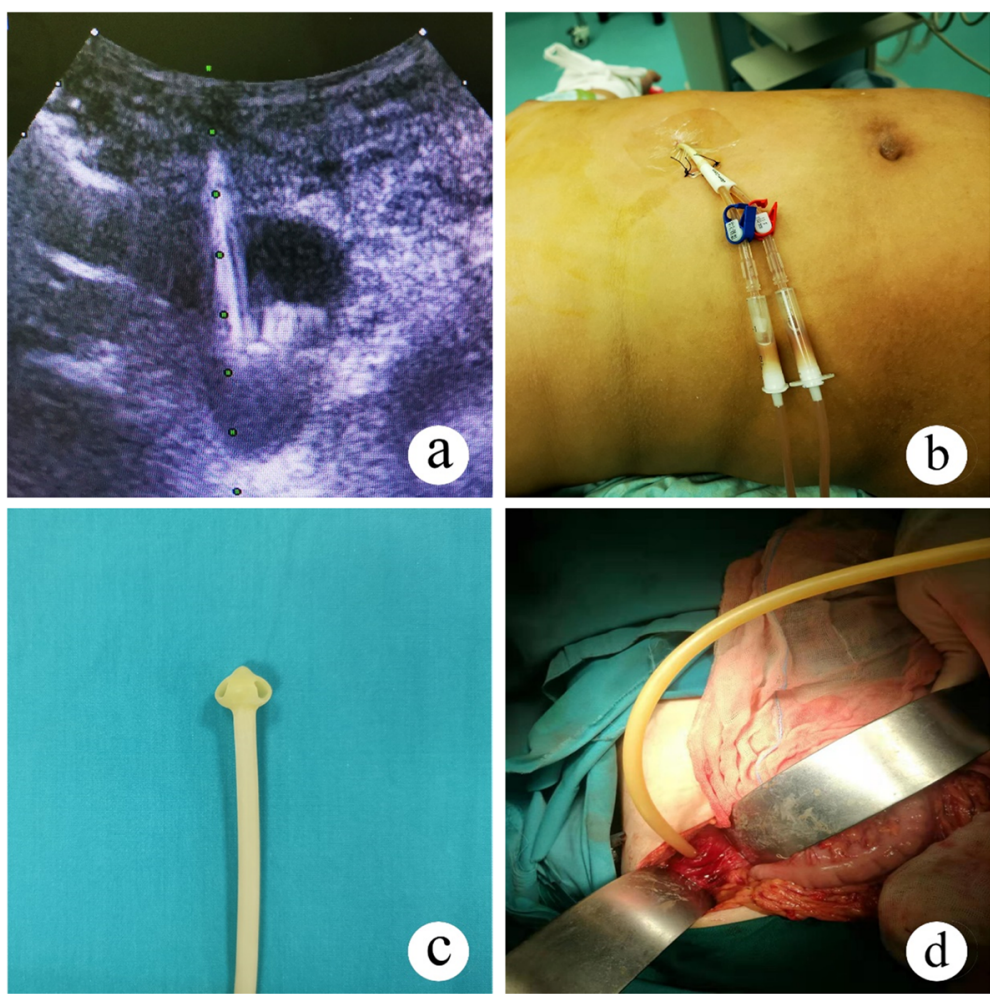

Fig. 3 Method for percutaneous and external drainage. a US-guided percutaneous drainage. b Abdominal percutaneous tube. c Umbrella-shaped corrugated rubber drain. $\mathbf{d}$ Using an umbrella-shaped corrugated rubber drain for external drainage

conservative treatment, internal drainage, such as
gastric-cyst and jejunum-cyst anastomosis, was performed.

\section{Outcome, discharge and follow-up}

Our primary outcome was treatment strategy, as defined above, including pancreatic tissue resection and operative interventions. Peritoneal lavage and drainage, external drainage and internal drainage were considered operative interventions. Secondary outcomes were mortality and major complications, including abdominal infection and PCs. Length of stay was also evaluated. The discharge criteria included the following: 1) no symptoms during oral intake; 2) US indicated a PC diameter less than $2 \mathrm{~cm}$ and no significant increase after oral intake; and 3) no evidence of infection based on laboratory findings. Normalization of serum amylase level was not included as an essential discharge criterion unless the value was over $200 \mathrm{U} / \mathrm{L}$ due to its limited value to reflect damage to the pancreas [11-13]. All children were followed up regularly at $2,4,8$ and 12 weeks after discharge in the outpatient department to monitor serum amylase, serum lipase and blood glucose, as well as to perform the abdominal US. The long-term prognosis was followed up by telephone in February 2020.

\section{Statistical methods}

Categorical variables were analyzed with the $\chi^{2}$ test, Fisher's exact test or Spearman's correlation analysis. Continuous variables with normal distributions are presented as the means \pm standard deviations and were analyzed with Student's t-test. Continuous variables with nonnormal distributions are presented as medians and ranges and were analyzed with the Mann-Whitney test. $P<0.05$ (2-sided) was considered significant. Statistical calculations were performed using a software program (IBM SPSS Package, version 22.0; IBM Corporation).

\section{Results}

\section{Demographic and imaging data}

During the study period, 20 children with grade III (16/ $20,80.0 \%)$ or IV $(4 / 20,20.0 \%)$ blunt pancreatic injuries met the inclusion criteria. Children with biliary tract injury $(n=1)$, who died without treatment $(n=1)$, or who refused treatment $(n=1)$ were excluded (Fig. 4). The average age at the time of injury was $6.9(3.3-12.3)$ years and $70.0 \%$ were males. The most common cause of injury was traffic accidents $(8 / 20,40.0 \%)$. Of these patients, $13(13 / 20,65.0 \%)$ had isolated pancreatic injuries and 7 $(7 / 20,35.0 \%)$ had pancreatic injuries combined with organ injuries (Table 2). The median time for the diagnosis of pancreatic injury was 2.5 (1-30) days. Thirteen 


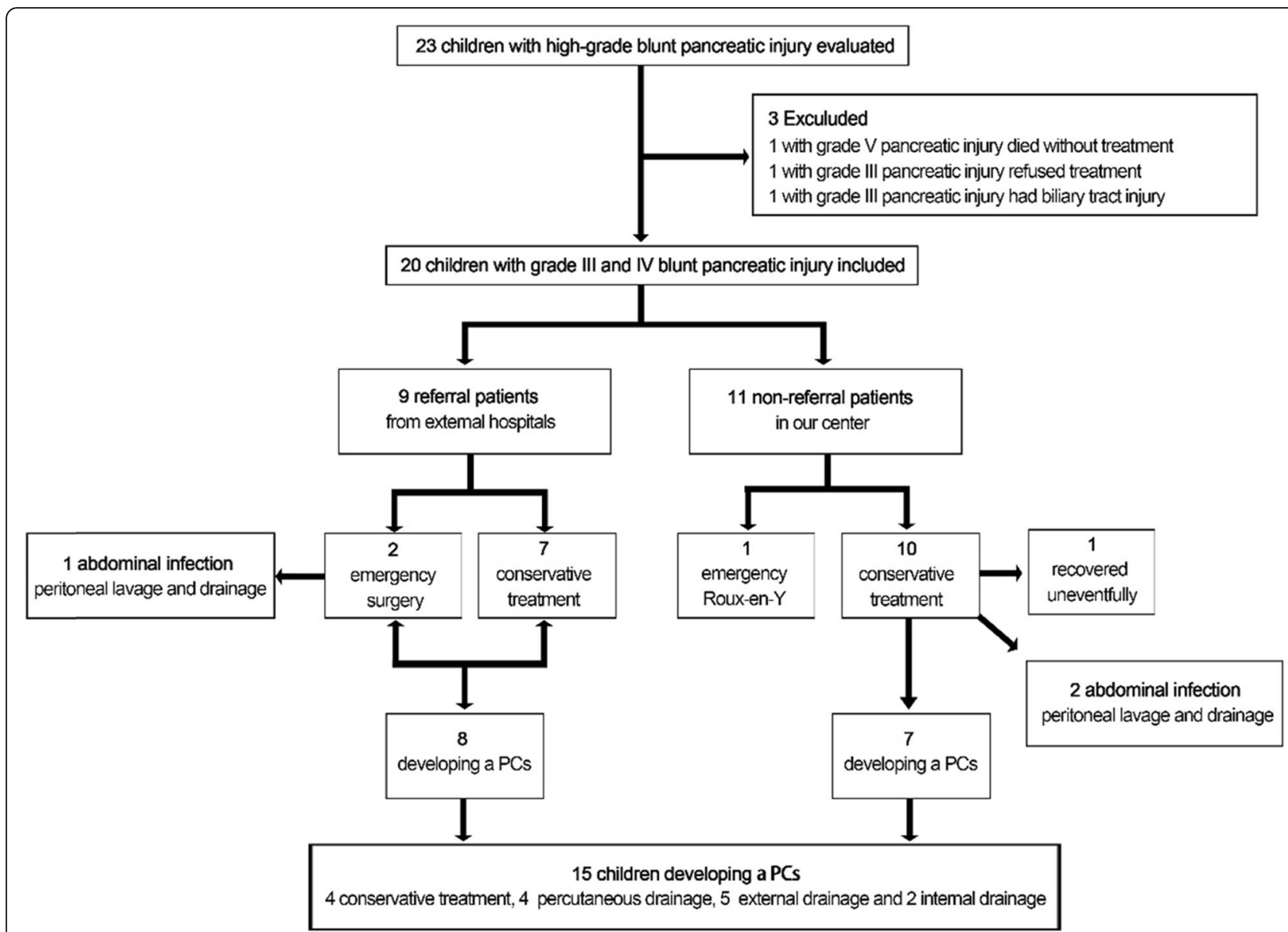

Fig. 4 Details of cohort formation from overall patients with high-grade blunt pancreatic injury from the National Center of Children's Health in Beijing, China

$(13 / 20,65.0 \%)$ patients had a delayed diagnosis $(\geq 24 \mathrm{~h}$ after injury). All children received the initial US with an accuracy of $65.0 \%(13 / 20)$, and there were no significant differences in accuracy between children with isolated injury and those with combined pancreatic injury $(9 / 13$ vs. $4 / 7, P=0.651)$. Sixteen children received CT with an accuracy of $68.8 \%(11 / 16)$, and there was a significant difference in accuracy between children with isolated injury and those with combined pancreatic injury (9/9 vs. $2 / 7, P=0.005)$. Five patients with isolated pancreatic injury received MRI, with an accuracy of $100.0 \%(5 / 5)$ (Table 3).

\section{Treatment of referral patients from external hospitals}

Nine children who presented with intractable symptoms, such as advanced peritonitis and PCs, after treatments at external hospitals were transferred to our center. One patient received emergency surgery at an external hospital due to a diagnosis of appendicitis. The patient was found to have a pancreatic injury during the operation and received abdominal drainage, which led to the development of PCs. The patient ultimately recovered through percutaneous drainage performed in our center. Another patient received emergency surgery due to a preoperative diagnosis of intestinal perforation but was not found to have a pancreatic injury at another external hospital, which resulted in severe abdominal infection. The patient later recovered through peritoneal lavage and drainage performed in our center. The remaining 7 patients were transferred to our center due to the development of PCs after conservative treatment at external hospitals, of whom 1 recovered after conservative treatment, 1 recovered through percutaneous drainage, 3 recovered through external drainage, and 2 had longer postinjury periods ( 45 days and 80 days) recovered at our center after receiving a gastric-cyst and jejunum-cyst anastomosis. The average length of stay of the above patients in our center was 33.8 (8-63) days.

\section{Treatment of non-referral patients}

Eleven children were admitted to our hospital directly after pancreatic injury. One child who had continued hemorrhagic shock ultimately received an emergency laparotomy and underwent Roux-en-Y drainage of the 
Table 2 Demographics of individual children with high-grade blunt pancreatic injury

\begin{tabular}{|c|c|c|c|c|c|}
\hline ID & Age (years) & Sex & Causes & Combined injuries & Follow-up time (years) \\
\hline 1 & 3.3 & Male & Traffic accident & Spleen & 9.6 \\
\hline 2 & 4.0 & Female & Traffic accident & Kidney, lung & 8.3 \\
\hline 3 & 4.1 & Male & Falling & Lower limb, liver & 1.8 \\
\hline 4 & 4.5 & Male & Unknown & - & 5.3 \\
\hline 5 & 4.7 & Female & Traffic accident & - & 3.4 \\
\hline 6 & 5.1 & Female & Abuse & - & 7.2 \\
\hline 7 & 5.9 & Female & Traffic accident & Hepatic, kidney, spleen, intestinal tract & 8.7 \\
\hline 8 & 6.0 & Male & Traffic accident & Kidney & 10.1 \\
\hline 9 & 6.8 & Female & Falling & - & 2.8 \\
\hline 10 & 6.8 & Female & Falling & Hepatic, duodenum, pylorus & 1.7 \\
\hline 11 & 7.0 & Male & Falling & - & 9.8 \\
\hline 12 & 7.0 & Male & Traffic accident & - & 9.5 \\
\hline 13 & 7.0 & Male & Falling & - & 8.4 \\
\hline 14 & 7.0 & Male & Traffic accident & Kidney, lung & 6.3 \\
\hline 15 & 8.0 & Male & Falling & - & 9.8 \\
\hline 16 & 8.8 & Male & Traffic accident & - & 8.6 \\
\hline 17 & 9.0 & Male & Traffic accident & - & 8.5 \\
\hline 18 & 9.0 & Male & Bicycle injury & - & 6.7 \\
\hline 19 & 12.0 & Male & Bicycle injury & - & 5.3 \\
\hline 20 & 12.3 & Male & Bicycle injury & - & 2.3 \\
\hline
\end{tabular}

distal pancreas. The remaining 10 children received conservative treatment, among whom 7 developed PCs, 2 developed an abdominal infection and 1 recovered uneventfully. Among the patients who developed PCs, 3 recovered after conservative treatment, 2 recovered through percutaneous drainage, and 2 recovered through external drainage. The patients who developed severe abdominal infection recovered after peritoneal lavage and drainage. The average length of stay of the above patients in our center was 47.5 (2369) days.

\section{Outcomes of all patients}

None of the children underwent pancreatic tissue resection. Fifteen $(15 / 20,75.0 \%)$ developed PCs, and $7(7 / 15,46.7 \%)$ of them received an operative intervention, including 5 external drainage and 2 internal drainage. Three $(3 / 20,15.0 \%)$ developed an abdominal infection, and they all recovered after abdominal irrigation and drainage. No patient was admitted to the ICU, and there was no death and no incidence of impaired pancreatic function during hospitalization.

Table 3 Diagnosis of isolated pancreatic injury and combined pancreatic injury

\begin{tabular}{|c|c|c|c|c|}
\hline & Isolated pancreatic injury $(n=13)$ & Combined pancreatic injury $(n=7)$ & All $(n=20)$ & $P$ \\
\hline Diagnosis time & & & & 1.000 \\
\hline$\leq 24 \mathrm{~h}$ after surgery & $5(38.5 \%)$ & $2(28.6 \%)$ & $7(35.0 \%)$ & \\
\hline$>24 \mathrm{~h}$ after surgery & $8(61.5 \%)$ & $5(71.4 \%)$ & $13(65.0 \%)$ & \\
\hline Initial ultrasound examination & $13(100.0 \%)$ & $7(100.0 \%)$ & $20(100.0 \%)$ & 0.651 \\
\hline Positive & $9(69.2 \%)$ & $4(57.1 \%)$ & $13(65.0 \%)$ & \\
\hline Initial CT examination & $9(69.2 \%)$ & $7(100.0 \%)$ & $16(80.0 \%)$ & 0.005 \\
\hline Positive & $9(100.0 \%)$ & $2(28.5 \%)$ & $11(68.8 \%)$ & \\
\hline Initial MRI examination & $5(38.5 \%)$ & $0(0.0 \%)$ & $5(25.0 \%)$ & - \\
\hline Positive & $5(100.0 \%)$ & $0(-)$ & $5(100.0 \%)$ & \\
\hline
\end{tabular}


All children were regularly followed up for 12 weeks after discharge, and 4 (4/20, 20.0\%) were diagnosed with local pancreatic atrophy by the abdominal US, without obvious abnormalities in serum amylase, serum lipase or blood glucose. With a mean follow-up time of 7.8 (1.710.1) years after discharge, no other long-term complications were observed.

\section{Discussion}

It is generally accepted in adults that grade I-II pancreatic injuries can be treated nonsurgically and that grade III or higher should receive resection management of the pancreas [14]. However, the optimal treatment of high-grade blunt pancreatic injuries is still controversial for pediatric surgeons worldwide because splenectomy is sometimes performed simultaneously during distal pancreatic resection, which does not meet parents' expectations [13, 15]. Therefore, all patients with blunt pancreatic injury at our center received initial conservative treatments in the last 10 years, except for children with gastrointestinal injury or continued hemorrhagic shock. This study was one of the largest studies to comprehensively describe the treatment strategies and clinical outcomes of nonresection management of the pancreas in children and verified the feasibility of nonresection management of the pancreas for children with high-grade blunt pancreatic injuries.

A review of our data shows that the male preponderance, the average age at the time and the common cause of injury in our sample were similar to those reported in previous studies $[1,3]$. The most common associated injury in our study was the kidney, which was different from other series. This finding may be closely related to different impacted positions. All patients were diagnosed within one month after injury, but the delayed diagnosis rate was significantly higher than in other studies [1]. This condition was mainly due to the 9 referral patients and the differences in diagnosis levels among the external hospitals.

The abdominal US is the primary examination method for patients with abdominal trauma but is generally insensitive to pancreatic injury diagnosis $[15,16]$. All patients in our study underwent the abdominal US after injury, but the positive rate of initial US was $65.0 \%$, which was related to the operator's diagnostic level. CT, especially CE-CT, is considered the gold standard for diagnosing pancreatic injury [17]. However, in the first $12 \mathrm{~h}$ after injury, CT is associated with a significant misdiagnosis rate, especially in grade III-V pancreatic injuries [18]. The main reasons were as follows: first, the initial CT may not be able to reveal direct signs such as injury of the main pancreatic duct; second, combined pancreatic injury can interfere with an accurate diagnosis, which was confirmed by our studies (28.5\%). Only when secondary findings such as peripancreatic effusion appeared with disease progression were the diagnosis became easier and more accurate $[15,19]$. Therefore, MRI is equally necessary for children with pancreatic injuries, especially in older children under stable conditions $[20,21]$. In our study, a child whose rupture of the main pancreatic duct was clearly visible on MRCP (Fig. 1e). This suggested that CT combined with MRCP may be a better option for diagnosing pancreatic injury [22]. Endoscopic retrograde cholangiopancreatography (ERCP) has been gradually recommended to diagnose closed pancreatic injury since 1986 [23, 24]. However, only half of the patients benefited from ERCP [25, 26]. Not all centers have the expertise to perform ERCP, such as our hospital. Further studies are needed to determine the benefits of ERCP in patients with pancreatic injuries.

Evidence to date clearly demonstrates that the incidences of early complications and the length of stay following surgical treatment and conservative treatment were similar [27, 28]. The main complication of the former treatment was infection, while the latter was dominated by PCs [29]. Three patients in our study developed a severe abdominal infection, including 1 after receiving emergency surgery at an external hospital and 2 during conservative treatment at our center, and they all recovered after abdominal irrigation and drainage in our center. The incidence of PCs in our study was similar to that reported in previous studies (approximately $70-80 \%$ ), and over $50 \%$ of them recovered by conservative management or simple US-guided percutaneous drainage $[9,30,31]$. Therefore, regardless of the kind of initial treatment used, we recommend that patients with complications such as PCs and severe abdominal infection be treated conservatively again and resolved with simple interventions if necessary.

In our study, after strictly following the suggested algorithm for the treatment of blunt pancreatic injury, we preserved the pancreas' integrity in most children as much as possible. According to the literature reports of other pancreatic-related diseases that require resection of the pancreas, the incidence of postoperative diabetes ranges from 20 to $83 \%$ [32, 33]. Furthermore, a pancreatic injury may induce gene expression, and patients receiving resection management of the pancreas should be monitored for pancreatic function for a long period of time [34]. Current studies in adults have confirmed that in patients with pancreatic injuries, partial pancreatic tissue resection does not stimulate the proliferation of the remaining islet $\beta$ cells, and glucose tolerance is significantly affected after the loss of $65 \%$ of islet $\beta$ cells [35]. Therefore, maintaining the pancreas' integrity in children with 
pancreatic injuries is critical to ensuring good longterm pancreatic function.

Short-term follow-up for patients with grade III-IV blunt pancreatic injuries showed favorable outcomes in our study. None of the patients were admitted to the ICU and died during hospitalization, and all had normal laboratory indicators after 12 weeks of regular follow-up, except for 4 with local pancreatic atrophy. However, we did not follow up with these children regularly because they came from all over the country. Therefore, regular long-term follow-up is essential in terms of pancreatic function, especially in patients with pancreatic atrophy.

This study has some limitations. First, the study was a retrospective study and included 9 referral patients from external hospitals, which affected the standardization of diagnosis and treatment. Second, some examination results, such as the initial amylase and lipase levels after abdominal trauma, from external hospitals were missing, which made the analysis difficult. Finally, the irregular outpatient follow-up after 12 weeks and lack of a control group of patients who underwent pancreatic resection could potentially influence the evaluation of pancreatic function and pancreatic pseudocysts' recurrence. Multicenter prospective studies with a regular long term follow-up schedule including pancreatic function indicators are expected to be performed in the future. However, this study is one of the largest single-center studies on grade III and IV blunt pancreatic injuries in children and thus has significant value in guiding the clinical diagnosis and treatment of children with high-grade pancreatic injuries.

\section{Conclusions}

Although nonresection management of the pancreas may lead to a longer hospital stay and a higher incidence of PCs, it could be a feasible option in children with grade III and IV blunt pancreatic injuries. They should be monitored for pancreatic function for a long period of time.

\section{Abbreviations \\ CT: Computed tomography; US: Ultrasound; AAST-OIS: Organ Injury Scale grading of the American Association for the Surgery of Trauma; CE- CT: Contrast-enhanced computed tomography; MRI: Magnetic resonance imaging; MRCP: Magnetic resonance cholangiopancreatography; ERCP: Endoscopic retrograde cholangiopancreatography; NPO: Nil-per-os; TPN: Total parenteral nutrition; EN: Enteral nutrition; PCs: Pancreatic pseudocysts}

\section{Acknowledgments}

We would like to thank Yueping Zeng for assistance in retrieving the hospital/ medical record numbers for the electronic patient records needed for data collection.

\section{Authors' contributions}

All authors read and confirmed the final manuscript. DZ contributed to data collections, data analysis, drafting the manuscript and writing the paper; JYY contributed to data collections, data analysis, drafting the manuscript and writing the paper; STS contributed to drafting the manuscript and writing the paper; WBP contributed to data analysis and drafting the manuscript; YJC contributed to study design, data analysis and writing the paper.

Funding

No source of funding for the study.

Availability of data and materials

All data generated or analyzed during this study are included in this published article.

Ethics approval and consent to participate

This study adheres to the ethical principles of the Declaration of Helsinki. It was approved by the Ethics Committee of Beijing Children's Hospital (2020k-12). For the presented retrospective data, the requirement to obtain informed consent was waived in accordance with the vote of the Ethics Committee.

Consent for publication

Not applicable.

\section{Competing interests}

The authors declare that they have no competing interests.

Received: 7 November 2020 Accepted: 29 January 2021

Published online: 11 February 2021

\section{References}

1. Englum BR, Gulack BC, Rice HE, et al. Management of blunt pancreatic trauma in children: review of the National Trauma Data Bank. J Pediatr Surg. 2016:51:1526-31.

2. Keller MS, Stafford PW, Vane DW. Conservative management of pancreatic trauma in children. J Trauma. 1997:42:1097-100.

3. Iqbal CW, St Peter SD, Tsao K, et al. Operative vs nonoperative management for blunt pancreatic transection in children: multiinstitutional outcomes. J Am Coll Surg. 2014;218:157-62.

4. Juric I, Pogoreli Z, Biocic M, et al. Management of blunt pancreatic trauma in children. Surg Today. 2009;39:115-9.

5. Moore EE, Cogbill TH, Malangoni MA, et al. Organ injury scaling, II: pancreas, duodenum, small bowel, colon, and rectum. J Trauma. 1990;30:1427-9.

6. Abdo A, Jani N, Cunningham S. Pancreatic duct disruption and nonoperative management: the SEALANTS approach. Hepatobil Pancreat Dis Int. 2013;12:239-43.

7. Figueiredo A, Goh BL, Jenkins S, et al. On behalf of the International Society for Peritoneal Dialysis. Clinical practice guidelines for peritoneal access. Perit Dial Int. 2010;30:424-9.

8. Wang G, Liu H, Xu L, et al. Effect of laparoscopic peritoneal lavage and drainage and continuous venovenous diahemofiltration on severe acute pancreatitis. J Laparoendosc Adv Surg Tech A. 2017;27:1145-50.

9. Vane DW, Grosfeld JL, West KW, et al. Pancreatic disorders in infancy and childhood: experience with 92 cases. J Pediatr Surg. 1989;24:771-6.

10. Panka L, Horváth $T$, Kovács $A$, et al. Treatment of pancreatic pseudocysts with ultrasound-guided percutaneous puncture and drainage. Orvosi Hetilap. 1992;133:1051-3.

11. Herman R, Guire KE, Burd RS, et al. Utility of amylase and lipase as predictors of grade of injury or outcomes in pediatric patients with pancreatic trauma. J Pediatr Surg. 2011;46:923-6.

12. Brasel KJ, Moore EE, Albrecht RA, et al. Western trauma association critical decisions in trauma. J Trauma Acute Care Sur. 2017:82:200-3.

13. Lin BC, Chen RJ, Hwang TL. Lessons learned from isolated blunt major pancreatic injury: surgical experience in one trauma Centre. Injury. 2019;50: 1522-8.

14. Ho VP, Patel NJ, Bokhari F, et al. Management of adult pancreatic injuries: a practice management guideline from the eastern association for the surgery of trauma. J Trauma Acute Care Surg. 2017;82:185-99.

15. Haider F, Al Awadhi MA, Abrar E, et al. Pancreatic injury in children: a case report and review of the literature. J Med Case Rep. 2017;11:217.

16. Brown MA, Casola G, Sirlin CB. Blunt abdominal trauma: screening US in 2693 patients. Radiology. 2001;218:352-8.

17. Melamud K, Lebedis CA, Soto JA. Imaging of pancreatic and duodena trauma. Radiol Clin N Am. 2015;53:757-71. 
18. Moschetta M, Telegrafo M, Malagnino V, et al. Pancreatic trauma: the role of computed tomography for guiding therapeutic approach. World J Radiol. 2015;7:415-20

19. Miele $\mathrm{V}$, Piccolo $\mathrm{CL}$, Trinci $\mathrm{M}$, et al. Diagnostic imaging of blunt abdominal trauma in pediatric patients. La Radiol Medica. 2016;121:409-30.

20. Lin BC, Chen RJ, Fang JF, et al. Management of blunt major pancreatic injury. J Trauma. 2004;56:774-8.

21. Caroline $\mathrm{H}$, Kocher MR. et al, The use of MRI digital subtraction technique in the diagnosis of traumatic pancreatic injury. Radiol Case Rep. 2019:14, 639-645.

22. Bosboom D, Braam AWE, Blickman JG, et al. The role of imaging studies in pancreatic injury due to blunt abdominal trauma in children. Eur J Radiol. 2006;59:3-7.

23. Hall RI, Lavelle MI, Venables CW. Use of ERCP to identify the site of traumatic injuries of the main pancreatic duct in children. Br J Surg. 1986;73: $411-2$.

24. Bhasin DK, Rana SS, Rawal P. Endoscopic retrograde pancreatography in pancreatic trauma: need to break the mental barrier. J Gastroentero Hepatol. 2009;24:720-8.

25. Rosenfeld EH, Vogel AM, Klinkner DB, et al. The utility of ERCP in pediatric pancreatic trauma. J Pediatr Surg. 2018;53:146-51.

26. Houben $\mathrm{CH}$, Ade-Ajayi $\mathrm{N}$, Patel $\mathrm{S}$, et al. Traumatic pancreatic duct injury in children: minimally invasive approach to management. J Pediatr Surg. 2007; 42:629-35.

27. Meier $\mathrm{DE}$, Coln $C D$, Hicks BA, et al. Early operation in children with pancreas transaction. J Pediatr Surg. 2001;36:341-4.

28. Wales PW, Shuckett B, Kim PCW. Long-term outcome after nonoperative management of complete traumatic pancreatic transaction in children. J Pediatr Surg. 2001;36:823-7.

29. Mora MC, Wong KE, Friderici J, et al. Operative vs nonoperative management of pediatric blunt pancreatic trauma: evaluation of the national trauma data bank. J Am Coll Surg. 2016;222:977-82.

30. Abdo A, Jani N, Cunningham SC. Pancreatic duct disruption and nonoperative management: the SEALANTS approach. Hepatobil Pancreat Dis Int. 2013:12:239-43.

31. Cheruvu CVN, Clarke MG, Prentice M, et al. Conservative treatment as an option in the management of pancreatic pseudocyst. Ann R Coll Surg Engl. 2003;85:313-6.

32. Lindholm EB, Alkattan AK, Abramson SJ, et al. Pancreaticoduodenectomy for pediatric and adolescent pancreatic malignancy: a single-center retrospective analysis. J Pediatr Surg. 2017;52:299-303.

33. Marchegiani G, Crippa S, Malleo G, et al. Surgical treatment of pancreatic tumors in childhood and adolescence: uncommon neoplasms with favorable outcome. Pancreatology. 2011;11:383-9.

34. Edwards MJ, Crudo DF, Carlson TL, et al. Pancreatic atrophy and diabetes mellitus following blunt abdominal trauma. J Pediatr Surg. 2013:48:432-5.

35. Menge BA, Tannapfel A, Belyaev O, et al. Partial pancreatectomy in adult humans does not provoke B-cell regeneration. Diabetes. 2008;57:142-9.

\section{Publisher's Note}

Springer Nature remains neutral with regard to jurisdictional claims in published maps and institutional affiliations.

Ready to submit your research? Choose BMC and benefit from:

- fast, convenient online submission

- thorough peer review by experienced researchers in your field

- rapid publication on acceptance

- support for research data, including large and complex data types

- gold Open Access which fosters wider collaboration and increased citations

- maximum visibility for your research: over $100 \mathrm{M}$ website views per year

At $\mathrm{BMC}$, research is always in progress.

Learn more biomedcentral.com/submissions 